\title{
OBSERVATIONAL STUDY OF FOREIGN BODIES IN DIGESTIVE TRACT
}

\begin{tabular}{ll}
\hline Medicine & \\
Dr. Alokendu Bose & Senior Resident, R. G. Kar Medical College And Hospital. Kolkata. \\
\hline $\begin{array}{ll}\text { Dr. Indranil } & \text { Medical Officer (Supy), Swasthya Bhawan, Gn-29 Sector-V, Salt Lake, Kolkata, West } \\
\text { Khatua* } & \text { Bengal. *Corresponding Author }\end{array}$ \\
\hline
\end{tabular}

Dr. Nayana
Sengupta

Sengupta

Dr. Debarshi Jana
Dy Patil Dental College Pune.

young scientist (DST) Institute of post-graduate medical education and research,

A.J.C. Bose road, kolkata-700020, west bengal, india.

\begin{abstract}
Background: Parent's laxness and lack of attention by leaving small objects at the reach of children contributes to this high incidence of foreign bodies. Ears, noses and throats are the most exposed orifices, hence the incidence of foreign bodies is also high in them. Problem of dealing with aspirated foreign body either swallowed or aspirated are since antiquity. In such cases, no definitive treatment was available and hence, the morbidity and mortality were very high.

Aim: To determine the incidence of foreign bodies in the upper aerodigestive tracts according to the age and sex among patients attending ENT department at TMH.

Material and methods: This Prospective study was carried out in the Department of Otorhinolaryngology, Department of Otorhinolaryngology, R. G. Kar Hospital, Kolkata, West Bengal.

Results: Complications after FB ingestion or removal are higher in lower SES group. Lower SES - 19/72(26.7\%) while high SES with $10 / 68(14 \%)$. There were statistically no significant difference among the patients according to their Complications when compared with their SES although the percentage of lower status group are more than higher, with $\mathrm{p}-$ value $=0.5533\{\mathrm{p}>0.05\}$.

Conclusion: Adults have more predilections for digestive tract foreign bodies which is mainly because of dietary habits and hasty eating.
\end{abstract}

\section{KEYWORDS}

Aerodigestive tract, Foreign body, Otorhinolaryngology, morbidity, mortality.

\section{INTRODUCTION}

Foreign bodies are common problem in pediatric otolaryngology and are frequently associated with significant severe complications. ${ }^{1}$ It is reported to be the most common cause of accidental death at home in children under 6 years of age. ${ }^{2}$ More than 600 sudden deaths of children caused by foreign body inhalation are reported each year in the United States alone and there must also be an untold number of traumas and near fatalities. The problem is likely to be of higher magnitude in India. These unfortunate occurrences can stem from a long list of causes, including: inadequate supervision, poor judgment, unsafe product design, unwise personal habits, and cultural practices.

Foreign body aspiration may occur at any age, however most of these accidents occur in the children below age three years. The high incidence in young children reflects their tendency to explore their world using their mouths. Furthermore, these children have not yet developed a full posterior dentition, and neuromuscular mechanisms for swallowing and airway protection may not be fully mature.

Adults may aspirate when alcohol, sedatives or head trauma alter their judgement or mental status, with cervicofacial trauma or when neurogenic disease or physical conditions, such as dentures, impair sensation or control of the food bolus. ${ }^{4}$

In other age group the main risk factors are primary neurological disorder and decreased gag reflexes due to Parkinsonism, senile dementia, strokes, seizures and alcohol intake. Other possible situations are surgical procedures under sedation, particularly dental procedures. ${ }^{5}$ Symptoms and signs produced depend upon the nature, size, location and time since lodgement of the foreign body in the tracheobronchial tree. A large foreign body occluding the upper airway may lead to sudden death whereas a small foreign body lodged in the bronchial tree may cause less severe symptoms.

In developing areas the higher prevalence of illiteracy, the lack of proper health education, superstitions, negligence on the part of parents and lack of availability of timely and expert medical help results in higher chances of under reporting as well as delayed or inadequate management of the foreign bodies in upper aerodigestive tract which accounts to grave complications. Hence, with the above facts kept in mind we propose to carry out a study of the epidemiological variations, incidence, prevalence, effect of psychological status of caregiver and patient, parity of mother and socioeconomical status of the patients with foreign bodies attending ENT department of R. G. Kar Hospital, Kolkata, West Bengal.

\section{AIMS \& OBJECTIVES}

AIMS:

To determine the incidence of foreign bodies in the upper aerodigestive tracts according to the age and sex among patients attending ENT department at R. G. Kar Hospital, Kolkata, West Bengal

\section{OBJECTIVES}

To investigate the incidence, types, sites and distribution of upper aerodigestive foreign bodies according to age, sex, socioeconomic status and parity of mother with respect to epidemiological variations.

\section{MATERIALAND METHODS}

The present study - 'EPIDEMOLOGICAL STUDY OF FOREIGN BODIES IN UPPER AERODIGESTIVE TRACT' was carried out in the Department of Otorhinolaryngology, R. G. Kar Hospital, Kolkata, West Bengal.

PERIOD OF STUDY: - One and half years, from August 2014 to December 2015

STUDY POPULATION:- All patients who were admitted in the ENT wards, ENT referrals and attended ENT outpatient clinic with history or symptoms and/or signs of foreign bodies insertion, ingestion or aspiration or diagnosis of foreign bodies and confirmed by Otorhinolaryngological examination and /or radiological examinations were included.

SAMPLE SIZE:- Taking the $\alpha$ at 0.05 and desired power of study is $80 \%$ the sample size needed is 140 .

\section{INCLUSION CRITERIA:}

1. Patients with history of ingestion of foreign body or with history of dysphagia.

2. Patients with history of aspiration or dyspnea or with history of stridor. 
3. Patients with history of aspiration or insertion of foreign body in the nose

4. Patients who accepted to sign the consent for study.

\section{EXCLUSION CRITERIA:}

Patients with any other cause of nasal discharge, stridor or dysphagia were excluded from the study.

\section{Statistical significance tests}

Depending on the nature of data categorical data these methods will be employed.

1. Student's paired T-test was used as the statistical tool to test for significance of observed mean differences.

2. Statistical analysis would be done using - Chi-square Test - A p value $<0.05$ was considered significant.

3. Student t-test was employed to compare for difference between two means. A p value $<0.05$ will be considered significant.

4. Test of Significance for Difference of Proportions. A p value $<0.05$ was considered significant.

5. For finding sensitivity, specificity, PPV, NPV, etc., we are using $2 \times 2$ diagnostic table.

\section{OBSERVATIONS AND RESULTS}

The study was conducted from August 2014 to December 2015 for a period of 1 and half years. Cases were categorized as nasal foreign bodies, digestive tract foreign bodies and lower airway foreign bodies. 77 cases in nasal cavity, 43 in digestive tract and 20 in lower airway were selected for study. Analysis of positive cases revealed the following observations.

In our study, out of 140 patients 77 were of foreign body nose, 43 of digestive tract and 20 were of airway tract.

The highest incidence of FB in present study was in age group less than 10 years. Nasal foreign bodies- $89.6 \%$ of our patients were of age less than 10 years, most common age group was under 3 years. Only $6.49 \%$ of FB nose were of age more than 41 years. Digestive foreign bodies- $41.8 \%$ of our patients were of age less than 10 years, $27.9 \%$ of FB digestive tract were of age group $11-40$ years. While $30.2 \%$ patients were older than 41 years. Airway foreign bodies- $90 \%$ of FB airway were of age less than 10 years, most common age group was under 3 years. Only $5 \%$ of FB airways were of age more than 11 years. For test of significance, here we use "Chi - square Distribution $\left\{\chi^{2}\right.$-Test $\}$ " $\chi^{2}$ $\mathrm{cal}=36.571\{$ at $95 \%$ confidence limit , with degree of freedom $(\mathrm{k}-$ 1) $(\mathrm{n}-1)=4)$ at 4 degree of freedom, $\chi 2$ tab $=9.488\} \chi^{2} \mathrm{cal}<\chi^{2}$ tab \{ $36.571>9.488$ \} at $5 \%$ level of significance. Hence, there were statistically significant difference among the patients according to their age because lower age proportion is much higher than higher age group, with $\mathrm{p}$ - value $\{\mathrm{p}<0.0001\}$.

In present study includes male predominance, $60 \%$, with male to female ratio $1.54: 1$. While in $\mathrm{FB}$ digestive tract male to female ratio is $1.15: 1$. There were statistically significant difference among the three groups according to their gender, with above value $\{\mathrm{p}<0.05\}$.

In our study, there was equal incidence of FB among the various socioeconomic statuses. We have clustered 1 and 2 socioeconomic status as upper status, and 3, 4 and 5 as lower status.. There were statistically no significant difference in the incidence of $\mathrm{FB}$ was seen according to their SES, with $p-$ value $=0.7721\{p>0.05\}$. Altogether there is no significant difference in time elapsed till presentation in ENT OPD of foreign bodies in upper and lower socioeconomic status, however percentage of lower socioeconomic status patients is much higher mainly in nose and digestive foreign bodies. Lower SES with $32 / 72(44 \%)$ and High SES with $15 / 68(22 \%)$. There was statistically no significant difference among the patients according to their Time Elapsed (for $\geq 1$ day ) with compared to socio - economic status although the percentage of lower status group are more than higher, with $p-$ value $=0.4510\{p>0.05\}$. There were statistically significant difference among the patients according to their Time Elapsed (for $\geq 1$ day ) with compared to SES although the percentage of lower status group are more than higher in digestive tract FB, with $\mathrm{p}-$ value $=0.0257\{\mathrm{p}<0.05\}$

Complications after FB ingestion or removal are higher in lower SES group. Lower SES - 19/72(26.7\%) while high SES with 10/68(14\%). There were statistically no significant difference among the patients according to their Complications when compared with their SES although the percentage of lower status group are more than higher, with $p-$ value $=0.5533\{p>0.05\}$.

We found that previous history of Nasal FB removal was more in Lower SES class with $34.2 \%$ while in Higher SES it is $25.6 \%$. There were statistically no significant difference among the patients according to their Previous History of F.B. removal when compared to SES, although the percentage of lower status group are more than higher, with $\mathrm{p}-$ value $=0.5014\{\mathrm{p}>0.05\}$

We found that attempts to remove nasal FB in home were much higher among Lower SES group (63.1\%) than Higher SES group(41\%). There were Statistically no significant difference among the patients according to their Attempts to F.B. removal at home when compared to SES, although the percentage of lower status group are more than higher for nasal FB removal at home, with $\mathrm{p}-$ value $=0.2684\{\mathrm{p}>0.05\}$.

It was found that there is no significant difference in the incidence of organic and inorganic foreign bodies in aerodigestive tract. There were statistically no significant difference among the patients according to their Nature of F.B.(organic) with compared to socio - economic status, although the percentage of lower status group are more than higher, with $\mathrm{p}-$ value $=0.7941\{\mathrm{p}>0.05\}$

It was found that bone was the most common foreign body in digestive tract 17/43(39.5\%). In that fish bone was most frequent $27.9 \%$.

\section{DISCUSSION}

Foreign bodies are common problem in pediatric otolaryngology and are frequently associated with significant severe complications. The early years of a child's life represent a phase of exploration and interaction with the environment. When they start moving independently, children start having access to a number of objects that they explore. This process encompasses, amongst other things, the placement of objects in orifices, such as the ears nose and throat.

\section{AGE OF PRESENTATION}

The highest incidence of FB in present study was in age group less than 10 years.

Digestive foreign bodies- $41.8 \%$ of our patients were of age less than 10 years,

$27.9 \%$ of FB digestive tract was of age group $11-40$ years. While $30 \%$ of patients were older than 41 years of age.

\begin{tabular}{|c|c|c|}
\hline Studies & Commonest age group & Percentage(\%) \\
\hline Rothmann BF et al(1980) & Less than 3 years & 77 \\
\hline Siddiqui MA et al(2000) & Less than 5 years & 85 \\
\hline Saki N et al ${ }^{8}(2009)$ & $1-3$ years & 54.8 \\
\hline Budensab et al(2012) $^{\text {Pud }}$ & $1-3$ years (74\%) & 74 \\
\hline Present study & $1-10$ years & $\mathbf{8 9 . 6}$ \\
\hline
\end{tabular}

The natural urge to explore the objects by mouth, lack of molar teeth to crush nuts, crying and playing while eating and lack of parental supervision contributes to this hazard in this age group

\section{GENDER INCIDENCE:}

In present study foreign body incidence is more common among male patients $(60 \%)$ as compared to females $(40 \%)$ with a $\mathrm{M}$ : F ratio of $1.54: 1$. This male preponderance in patients with foreign body aspiration is widely reported in literature.

In cases of nasal and airway foreign bodies the incidence of males is around $63 \%$. While in digestive foreign bodies our incidence percentage dropped to $53 \%$ and females $46 \%$. The ratio was $1.15: 1$. This may be due to high incidence of fish bone foreign bodies in females of this area.

\begin{tabular}{|c|c|c|c|}
\hline Studies & $\begin{array}{c}\text { Male } \\
\text { patients no. }\end{array}$ & $\begin{array}{c}\text { Female Patients } \\
\text { no. }\end{array}$ & M:F ratio \\
\hline Aliakbar R(2008) & 31 & 14 & $2.21: 1$ \\
\hline Saki N et al $^{\mathbf{8}} \mathbf{( 2 0 0 9 )}$ & 644 & 371 & $1.73: 1$ \\
\hline Budensab et al' (2012) $^{\mathbf{9}}$ (2) & 75 & 40 & $1.87: 1$ \\
\hline Present study $^{2}$ & 30 & 20 & $1.5: 1$ \\
\hline
\end{tabular}

The exact reason for this however, remains unclear, but it is probably attributed to the fact that male children spend more time playing outside, unsupervised by the guardians as compared to the girls.

Somanath BP et $\mathrm{al}^{10}$ attributed to this high incidence in boys, to their inquisitive nature. 
TYPES OF FOREIGN BODIES:

Digestive tract foreign bodies: Bones 39.5\% were the most common followed by coin $23 \%$ and denture $7 \%$ in our study.

Shivakumar AM, Naik, Prashanth KB, Hongal GF, Chaturvedy et al ${ }^{11}$ study showed that, of the total number of 152 patients, of which 104 were children and 48 were adults with ingested foreign body, blunt foreign body was common in children, whereas meat with bone was common in adults which correlate with our study.

\section{SITE OF FOREIGN BODY:}

Digestive tract foreign bodies: In our study $55 \%$ of the cases were in cricopharynx, $13 \%$ were in oesophagus while in $21 \%$ of cases the site was pyriform sinus.

In a study by Shivakumar AM, Naik, Prashanth KB, Hongal GF, Chaturvedy et $\mathrm{al}^{11}$, of the total number of 152 patients, most of blunt foreign body in children $83.5 \%$ were impacted in post cricoid region whereas in adults, the foreign bodies $37.5 \%$ were seen in upper oesophagus which correlates with our study.

\section{SIGNS AND SYMPTOMS OF PRESENTATION}

Digestive tract foreign bodies: Throat pain $100 \%$ was the most common symptom followed by dysphagia $58 \%$ followed by drooling of saliva in $48.8 \%$ and vomiting in $55 \%$ of cases. This may be due to injury by bone, infection, congestion and muscle spasm.

On examination foreign body sensation was seen in $95 \%$, pooling of saliva in $51 \%$ of cases.

Dysphagia was seen in $36 \%$ of cases in the study by Anupam Mishra et $\mathrm{al}^{12}$ series. However, they make no mention of throat pain.

In a study of 162 paediatric cases of aero-digestive foreign bodies studied over five years dysphagia was seen in $55.55 \%$ of the cases which is almost similar to our study.

\section{CONCLUSION}

Foreign bodies in the upper aerodigestive tract are a common clinical problem in otolaryngological practice as evident in this study. Though many doesn't pose an immediate problem of airway, some of them are serious and life threatening emergencies.

1. Adults have more predilection for digestive tract foreign bodies which is mainly because of dietary habits and hasty eating.

2. Proper history and examination are the key components to diagnose foreign bodies.

3. Otolaryngologists should categorise high risk patients on the basis of parity of mother, socioeconomic status and education of care giver, and they should be examined thoroughly.

4. Educating the parents about keeping away the articles from the reach of children and to observe the activity of a child will prevent the higher incidence of foreign body in the children

5. High risk patients should be counseled properly about signs and symptoms, health education and family planning.

6. Education is the key element which can bring down the burden of foreign bodies.

Table: Type of foreign bodies in digestive tract $(n=43)$

\begin{tabular}{|l|l|l|}
\hline Nature of FB & No. of patients & Percentage \\
\hline Fish bone & 12 & $27.91 \%$ \\
\hline Coin & 10 & $23.26 \%$ \\
\hline Mutton bone & 4 & $9.30 \%$ \\
\hline Denture & 3 & $6.98 \%$ \\
\hline Safety pin & 3 & $6.98 \%$ \\
\hline Custard apple seeds & 2 & $4.65 \%$ \\
\hline Metal wire & 2 & $4.65 \%$ \\
\hline Guava & 1 & $2.33 \%$ \\
\hline Jewelry & 1 & $2.33 \%$ \\
\hline Nail & 1 & $2.33 \%$ \\
\hline Pen cap & 1 & $2.33 \%$ \\
\hline Ring & 1 & $2.33 \%$ \\
\hline
\end{tabular}

\section{REFERENCE}

Sharif S, Roberts G, Phillips J. Transnasal penetrating brain injury with a ball-pen. British journal of neurosurgery. 2000;14(2):159-60.

2. Khan AR, Khan NS. Management of Whistle as a Foreign body Tracheobrocnchial Tree. JPMI(YR). 2011;18(4):JPMI(YR); 18(4):602-6.

3. Aliakbar Rahbarimanesh, Elaheh Noroozi, Mansour Molaian, Piman Salamati. Foreign Body Aspiration: A five-year Report in a Children's Hospital. Iranian Journal of
Pediatrics. 2008:2.

4. JNG. E. Foreign bodies in larynx and trachea. In: In: Kerr e, editor. Scott-Brown's Otolaryngology. 6. 6th edition ed. London: Butterworth - Heinemann; 1997. p. 1-11.

5. Asif M, Shah SA, Khan F, Ghani R. Analysis of tracheobronchial foreign bodies with respect to sex, age, type and presentation. Journal of Ayub Medical College, Abbottabad JAMC. 2007;19(1):13-5.

6. Rothmann BF, Boeckman CR. Foreign bodies in the larynx and tracheobronchial tree in children. A review of 225 cases. The Annals of otology, rhinology, and laryngology. 1980;89(5 Pt 1):434-6.

7. Siddiqui MA, Banjar AH, Al-Najjar SM, Al-Fattani MM, Aly MF. Frequency of tracheobronchial foreign bodies in children and adolescents. Saudi Med J. 2000;21(4):368-71

8. Saki N, Nikakhlagh S, Rahim F, Abshirini H. Foreign body aspirations in infancy: a 20 year experience. International journal of medical sciences. 2009;6(6):322-8.

9. Budensab.A.H AV, Bagalkot PS et. al. Pattern of foreign body aspiration in children- an experience at SDM college of medical sciences and hospital. Int J Health Sci Res. 2012;2(8):20-8

10. Somanath BP, Singhi S. Airway foreign bodies in children. Indian Pediatr 1995;32(8):890-7.

11. Shivakumar AM, Naik AS, Prashanth KB, Yogesh BS, Hongal GF. Foreign body in upper digestive tract. Indian J Pediatr. 2004;71(8):689-93.

12. Mishra A, Shukla GK, Bhatia N. Aerodigestive foreign bodies. Indian J Pediatr. 2000;67(6):429-33. 